\title{
Bacterial microflora of the chicken embryos and newly hatched chicken ${ }^{*}$
}

\author{
M. Kizerwetter-Świda ${ }^{1}$ and M. Binek \\ Department of Pre-Clinical Sciences, Faculty of Veterinary Medicine, \\ Warsaw University of Life Sciences \\ Ciszewskiego 8, 02-786 Warsaw, Poland
}

(Received 20 February 2006; revised version 13 March 2008; accepted 8 April 2008)

\begin{abstract}
The purpose of the study was to examine of bacteria present in chicken embryos and newly hatched chicks. The bacteria were determined quantitatively in caecal contents, liver and yolk sac of 25 embryos at 18 day of incubation, 25 embryos at 20 day incubation, and 25 newly hatched chicks. Gram-positive cocci belonging to the Enterococcus genus dominated in all samples examined and their population number amounted from $10^{2}$ to $10^{6} \mathrm{CFU} / \mathrm{g}$ in caecal contents, $10^{2}-10^{4} \mathrm{CFU} / \mathrm{g}$ in yolk sac, and $10^{3} \mathrm{CFU} / \mathrm{g}$ in liver. Other bacteria present in some samples were: Staphylococcus sp. $10^{2}-10^{4} \mathrm{CFU} / \mathrm{g}$, E. coli $10^{6} \mathrm{CFU} / \mathrm{g}$, C. tertium $10^{5} \mathrm{CFU} / \mathrm{g}$, Klebsiella sp. $10^{4} \mathrm{CFU} / \mathrm{g}$, and Enterobacter sp. $10^{2} \mathrm{CFU} / \mathrm{g}$. The results obtained indicate that the profile of gut microflora becomes more differentiated and their population number of particular groups higher with the age of embryos. Moreover, potentially pathogenic bacteria, including anaerobic Clostridium tertium may be isolated already during hatching period, suggesting the possibility of infection of embryos and newly hatched chicks.
\end{abstract}

KEY WORDS: chicken, embryos, hatching, gastrointestinal microflora

\section{INTRODUCTION}

Bacterial colonization of the alimentary tract in chickens begins usually during hatching process. The contact with bacteria from the environment, mainly through feed and water, allows the chick to develop intestinal flora with the first days after hatching. As soon as eggs are laid, bacteria penetrate the eggshell and other shell barriers (Berrang et al., 1999; Cook et al., 2003). Moreover, there is possibility

\footnotetext{
* Supported by the Ministry of Science and Higher Education, Grant No. 2 P06K 02026

${ }^{1}$ Corresponding author: e-mail: magdakiz@wp.pl
} 
of transovarian transmission for pathogenic bacteria, including Salmonella Enteritidis. Contamination of table eggs by Salmonella is essential for public health risk associated with consumption of infected eggs (Berrang et al., 1999). In contrast, contamination of hatching eggs may implicate invasion of these bacteria into egg contents and chicken embryos (Montgomery et al., 2005). There is limited number of reports in the literature indicating such route of infection of chicken embryos and newly hatched chickens (Tankson et al., 2002; Rosario et al., 2004). Furthermore, available results are based only on qualitative experiments.

The purpose of this study was quantitative examination of bacteria including anaerobs in caecal contents, livers and yolk sacs of broiler embryos and newly hatched chickens.

\section{MATERIAL AND METHODS}

\section{Embryos and chickens}

Twenty five broiler embryos at 18 day of incubation, 25 embryos at 20 day of incubation and 25 newly hatched chickens were obtained from a local hatchery. Only alive and completely developed embryos were selected for experiments. Caecum, liver and part of a yolk sac were taken aseptically for bacteriological examination.

\section{Bacteriological examination}

Direct microscopy smears were prepared from liver and mucosal scrapings from caecum followed by Gram staining. Caecal contents, livers and yolk sacs were collected aseptically and homogenized. Serial 10 -fold dilutions were prepared in PBS. Volumes of $0.1 \mathrm{ml}$ of each dilution were spread on freshly prepared agar media. Three replicate plates for each dilution were inoculated.

Following media and incubation conditions were used:

- blood agar (BioMérieux) for culture of aerobic bacteria (Staphylococcus sp. and Micrococcus sp.), incubated at $37^{\circ} \mathrm{C}$ for $24 \mathrm{~h}$ in aerobic conditions,

- Mac Conkey agar (BioMérieux) for culture of enteric Gram-negative bacteria, incubated at $37^{\circ} \mathrm{C}$ for $24 \mathrm{~h}$ in aerobic conditions,

- Kanamycin Esculin Azide Agar (Merck) for culture of enterococci, incubated at $37^{\circ} \mathrm{C}$ for $48 \mathrm{~h}$ in microaerophilic atmosphere generated by $\mathrm{BBL}^{\mathrm{TM}} \mathrm{CampyPak}$ Plus system (Becton Dickinson),

- TSC (Merck) supplemented with D-cykloserine $(0.4 \mathrm{mg} / \mathrm{ml})$ for culture of Clostridium sp., incubated at $37^{\circ} \mathrm{C}$ for 48 to $72 \mathrm{~h}$ in anaerobic atmosphere generated by $\mathrm{BBL}^{\mathrm{TM}}$ GasPak system (Becton Dickinson). 
Bacterial counts were calculated as colony forming units (CFU) per gram of sample established with the aid of plate count method. Different colony types were enumerated and isolated in pure culture. The identification of the isolated colonies was performed using standard bacteriological procedures described by Malicki and Binek (2004). Following criteria for identification were applied: colony character, cell morphology, Gram stain and API tests (BioMérieux).

\section{RESULTS}

The results from bacteriological examination of embryos and newly hatched chickens are shown in Table 1, Figures 1 and 5. Only single Gram-positive cocci were observed on smears prepared from caecal contents of 18 day embryos (Figure 1). There were no visible microorganisms on smears prepared from livers. Enterococcus sp. were found in caecal contents of 5 embryos, Staphylococcus sp. in 5 embryos and Micrococcus sp. in 2 embryos, with average number $1.9 \times 10^{2} \mathrm{CFU} / \mathrm{g}$, $2.78 \times 10^{2} \mathrm{CFU} / \mathrm{g}$ and $1 \times 10^{2} \mathrm{CFU} / \mathrm{g}$ of caecal contents, respectively (Table 1). Enterococcus sp. (5 embryos) and Staphylococcus sp. (2 embryos) were found in yolk sac, with average number $1.06 \times 10^{2} \mathrm{CFU} / \mathrm{g}$ and $1.13 \times 10^{2} \mathrm{CFU} / \mathrm{g}$ of yolk sac contents. There was also single embryo, where Micrococcus sp. were found in yolk sac contents, reaching $1.5 \times 10^{2} \mathrm{CFU} / \mathrm{g}$. The number of enterococci isolated from the liver of one embryo at 18 day of incubation reached $1 \times 10^{2} \mathrm{CFU} / \mathrm{g}$ of liver tissue.

Second group of embryos at 20 day of incubation have had more numerous microflora, composed mostly by Gram-positive cocci and in single cases by members of Enterobacteriaceae family. Direct smears prepared from caecal contents reveled numerous Gram-positive cocci, apart from one embryo, where sporeforming Gram-positive rods were also observed (Figure 2).

Enterococci were the most often isolated from caecal contents of 14 embryos at 20 days of incubation with average number $1.3 \times 10^{5} \mathrm{CFU} / \mathrm{g}$. Additionally, there were also Staphylococcus sp. in 2 embryos with average number $3.66 \times$ $10^{4} \mathrm{CFU} / \mathrm{g}$. E. coli and Acinetobacter sp. were isolated from caecal contents of single embryos, with number $1.6 \times 10^{3} \mathrm{CFU} / \mathrm{g}$ and $1.1 \times 10^{3} \mathrm{CFU} / \mathrm{g}$. Unusually high level of Enterococcus sp. $5 \times 10^{5} \mathrm{CFU} / \mathrm{g}$ was detected in caecal contents of embryo, where we have observed spore-forming Gram-positive rods. However, the spore-forming rods, observed on direct smear were not isolated on TSC agar, because of extreme overgrowth of Enterococcus sp.

Bacteria isolated from yolk sacs of embryos at 20 day of incubation have been identified as Enterococcus sp. (10 embryos), Staphylococcus sp. (2 embryos), Enterobacter sp. (1 embryo) and their number reached $1.09 \times 10^{4} \mathrm{CFU} / \mathrm{g}, 2.72 \times 10^{3} \mathrm{CFU} / \mathrm{g}$ and $2.5 \times 10^{2} \mathrm{CFU} / \mathrm{g}$, respectively. Following microorganisms have been found in livers of embryos: Enterococcus sp. (6 embryos) and Enterobacter sp. (1 embryo). 


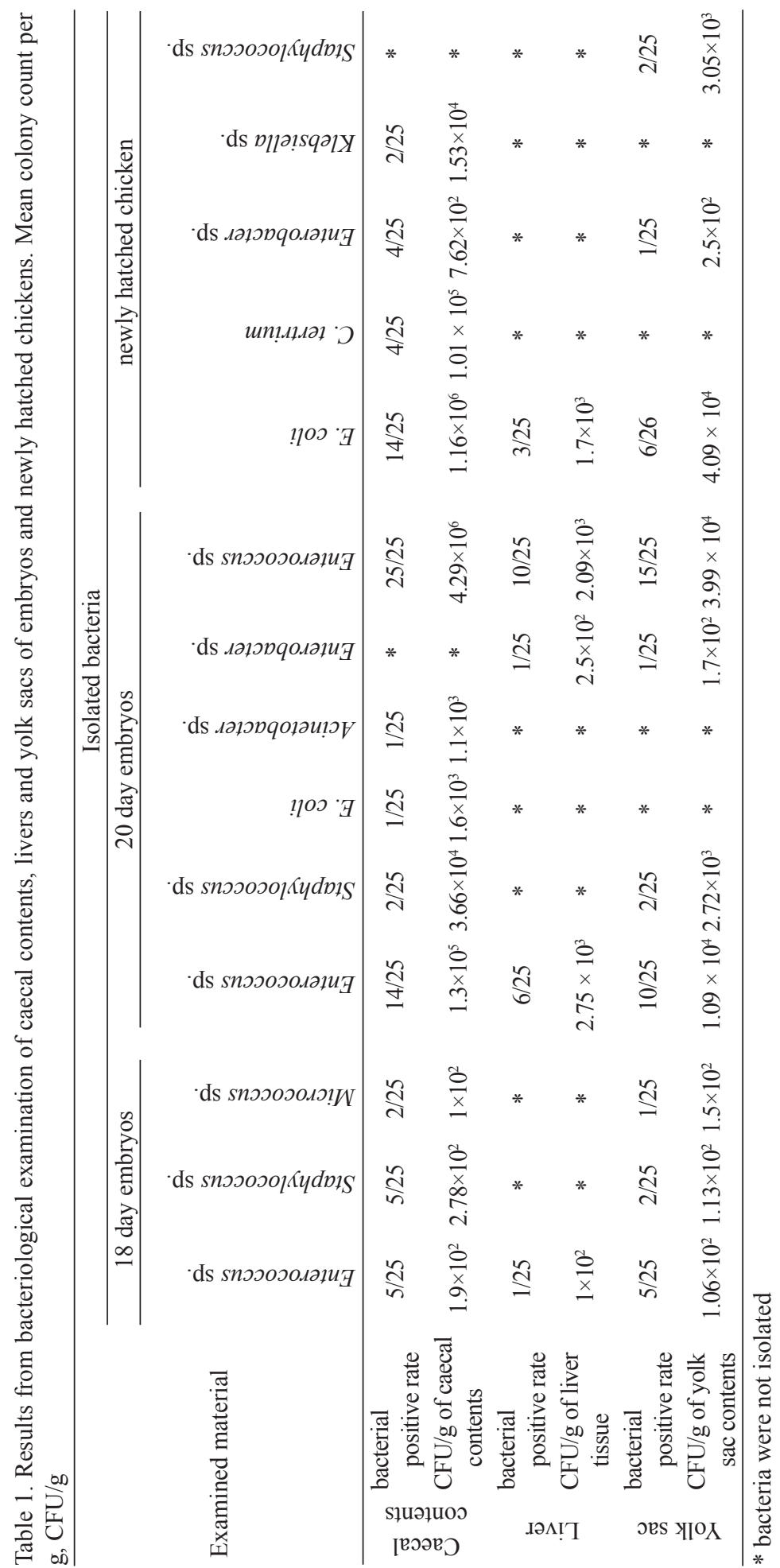




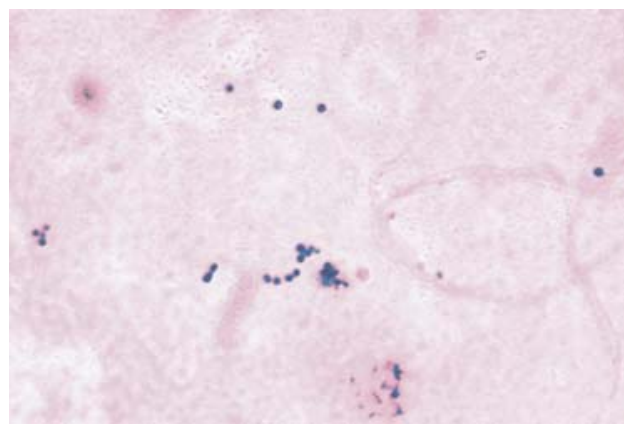

Figure 1. Direct smear prepared from caecal contents of chicken embryo (18 day of incubation), stained by Gram's method, magnification $1000 \mathrm{x}$
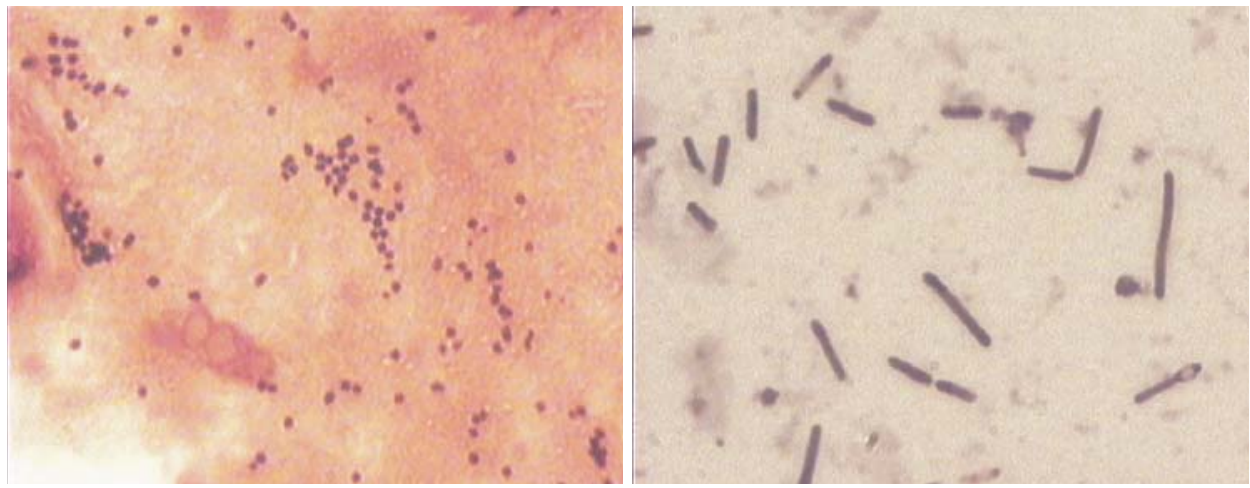

Figure 2. Direct smear prepared from caecal contents of chicken embryo (20 day of incubation), stained by Gram's method, magnification $1000 \mathrm{x}$
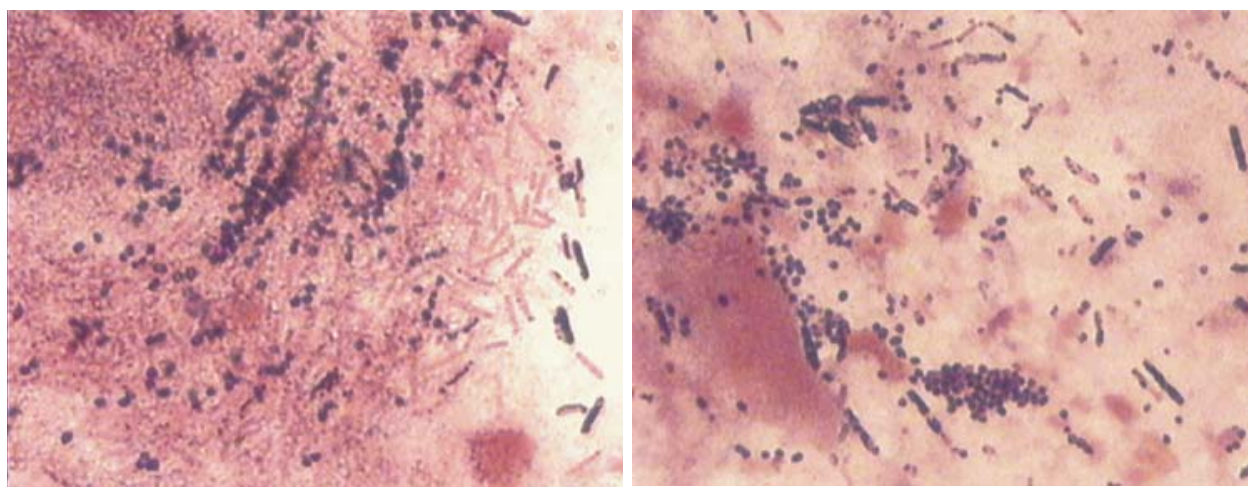

Figure 3. Direct smear prepared from caecal contents of newly hatched chicken stained by Gram's method, magnification $1000 \mathrm{x}$ 

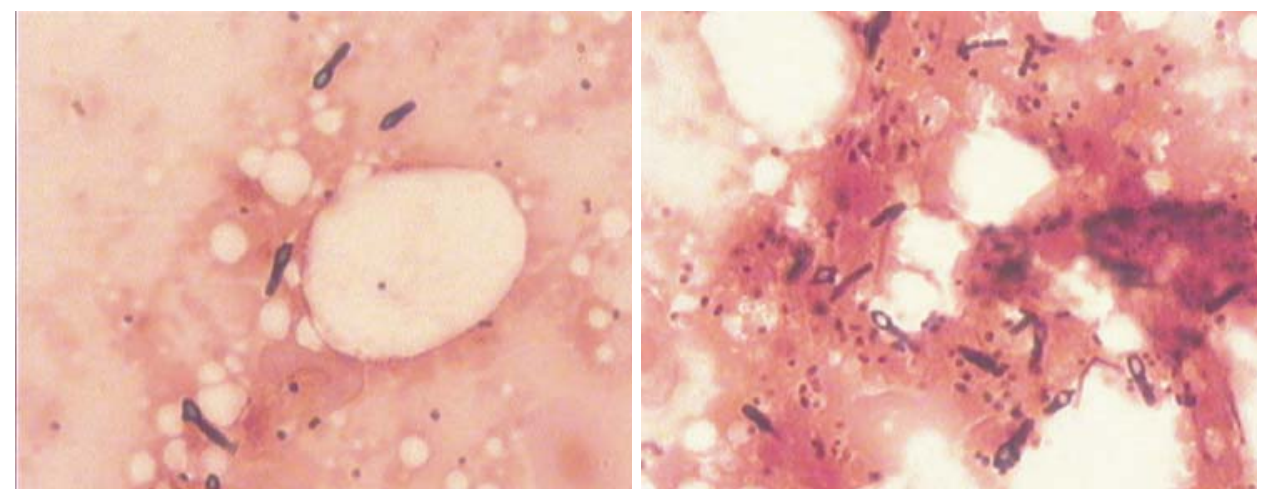

Figure 4. Direct smear prepared from livers of newly hatched chickens stained by Gram's method, magnification $1000 \mathrm{x}$

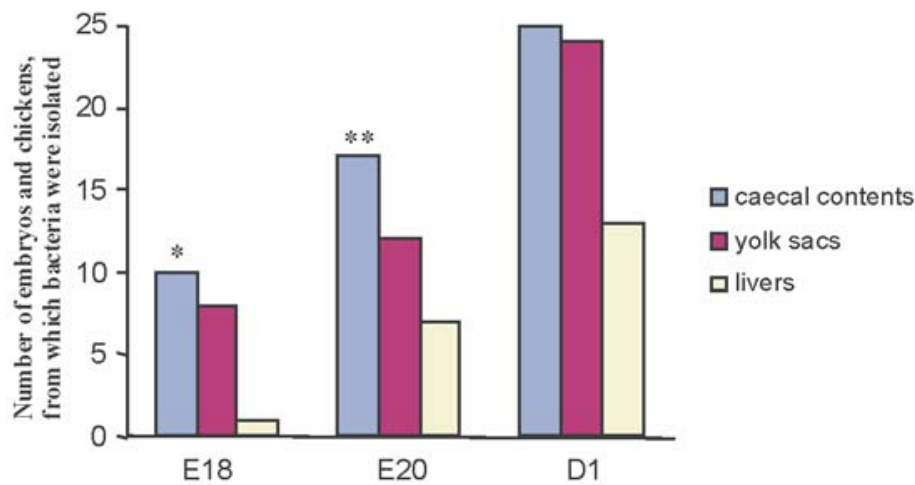

Figure 5. Number of chicken embryos and newly hatched chickens, from which bacteria were isolated from caecal contents, yolk sacs and livers. E18 - embryos at 18 day of incubation, E20 - embryos at 20 day of incubation, D1 - post hatching

* - the number of bacterial positive rate is lower as presented in Table 1, because bacteria belonging to three different groups were isolated from one embryo

** - the number of bacterial positive rate is lower as presented in Table 1, because bacteria belonging to two different groups were isolated from one embryo

The most complex microflora was isolated from chickens $3 \mathrm{~h}$ after hatching. Gram-positive cocci were isolated from caecal contents, livers and yolk sac (Table 1). Gram-positive cocci have been observed on direct smears prepared from caecal contents as well as from livers. In four cases numerous spore-forming Gram-positive rods were also present on smears from caecal contents (Figure 3) and livers (Figure 4).

Gram positive cocci belonging to Enterococcus sp. have been isolated from caecal contents each of 25 examined chickens, with average number $4.29 \times 10^{6}$ $\mathrm{CFU} / \mathrm{g}$. Additionally, E. coli were present in 14 chickens with average number 
$1.16 \times 10^{6} \mathrm{CFU} / \mathrm{g}$. Also Enterobacter sp. (4 chickens) and Klebsiella sp. ( 2 chickens) were isolated from caecal contents.

The following bacteria were isolated from livers of young chickens: Enterococcus sp. (10 chickens) and E. coli (3 chickens). Bacterial microflora of yolk sack after hatching consisted of Enterococcus sp. (15 chickens), E. coli ( 6 chickens), Staphylococcus sp. (2 chickens) and Enterobacter sp. (1 chicken).

Bacteriological examination of four chickens, where spore-forming Grampositive rods were observed, allowed obtaining on TSC agar supplemented with D-cykloserine anaerobic rods, with average number $1.01 \times 10^{5} \mathrm{CFU} / \mathrm{g}$ of caecal contents. All isolated strains were identified with API 20A as Clostridium tertium $(\% \mathrm{id}=98.9)$.

\section{DISSCUSION}

In transovarial infection bacteria are transmitted from the ovary or other part of the reproductive tract to the yolk. Moreover, penetration of pathogenic bacteria to the egg contents may appear during incubation period, leading to infection of embryo. Yolk sack infection (YSI) is economically important disease since it increases young chicken's mortality ratio during first week of life. Birds that survive YSI show poor weight gain as well as poor carcass quality. Factors affecting bacterial penetration through the egg shell include : faecal contamination of shells, lack of hygiene at the farm, incubation of eggs with eggshell defects, collection of eggs laid on the floor or inappropriate egg disinfection (Rosario et al., 2004).

Several reports were found in the literature evaluating bacterial microflora of chicken eggshells. It was reported by Cook et al. (2003), that Staphylcoccus sp., Enterococcus sp. and Micrococcus sp. are predominate bacteria isolated from eggshell. However, these microorganisms, except $S$. aureus and $E$. faecalis do not appear to be pathogenic for embryos and newly hatched chickens. Additionally, above mentioned authors showed that Gram-positive rods, Gram-positive cocci and Enterobacteriaceae are the major contaminants on the eggshell. By contrast, microbiota of egg albumen and yolk consist mostly of Gram-positive cocci, indicating their ability to invade through the eggshell.

In contrast, there is a limited number of publications covering bacterial microflora of chicken embryos and newly hatched chickens. In general, our results are in line with these uncommon reports. Results presented in this study provide quantitative analysis of bacterial counts from caecal contents, livers and yolk sacs, including anaerobic microorganisms. In our findings Gram-positive cocci were present in some embryos at 18 and 20 day of incubation; however Enterococcus 
sp. were most common. Enterobacteriaceae were isolated only in single cases. The number of bacteria were higher in embryos one day before hatching as compared with those on 18 day of incubation. Chickens were proved to have the most complex microflora, including significant E. coli presence. Binek et al. (2000) reported isolation of Enterococcus sp., Micrococcus sp. and Bacillus sp. from colon of chicken embryos at 17, 18 and 19 day of incubation. Similarly, Tankson et al. (2002) determined the bacterial microflora in heart and lungs of embryos and young chickens and proved that bacteria could be isolated from healthy chickens starting from 17 day of incubation, enterococci were isolated the most frequently.

In the present study Enterococcus sp. were the most often isolated from embryos and chickens. Enterococcus faecalis is opportunistic, Gram-positive, facultative anaerobe, found in the intestinal tract of humans and many animals including chicken. It is suggested that E. faecalis is as one of the etiological agents of pulmonary hypertension syndrome (PHS) in broiler chickens, which have become a serious problem in fast growing broilers recently (Tankson et al., 2001). PHS occurs when blood pressure in the pulmonary tree increases. Back pressure causes that right ventricle of the heart become overworked. As a result it becomes hypertrophic and abdominal cavity is full of fluid. It is well proved, that challenge with $E$. faecalis caused pulmonary hypertension, however the role of $E$. faecalis in PHS is not fully understood. It should be taken under consideration, that embryos and chickens, from which Enterococcus sp. were isolated, are at high risk of PHS.

Ultimately, the most interesting point of our findings was the isolation of anaerobic Clostridium tertium from newly hatched chickens connected with significant numbers of Enterococcus sp. in examined organs. Clostridium tertium were obtained from 4 newly hatched chickens. It suggested that spore forming bacteria are able to resist disinfection process and contaminate egg shells. During incubation they can penetrate the egg and infect embryo.

C. tertium is non-toxin-producing, aerotolerant microorganism, which is usually considered as nonpathogenic (Steyaert et al., 1999; Miller et al., 2001). However, there are reports of this species causing bacteraemia, concerning in most cases neutropenic people. Silvera et al. (2003) proved its ability to produce mild enteritis in cattle in experimental conditions. C. tertium has been also reported as a cause of megacolon and chronic diarrhoea in cockatoo (Hess et al., 1998). Based on the analysis of the results reported here, it can be concluded, that C. tertium appears to be an emerging pathogen in veterinary. Furthermore, its ability to produce spores, aerotolerant nature, ability to cause diarrhoea in animals and presence in gastrointestinal tract of healthy people and animals, make it is a possible food-contaminating microorganisms. Additional experiments would be 
necessary to determine the prevalence of $C$. tertium infections in embryos and chickens.

\section{CONCLUSIONS}

In conclusion, it is reasonable to assume that bacteria, including spore-forming C. tertium could be isolated from gastrointestinal tract of chicken embryos and newly hatched chickens. These results tend to support the possibility that $C$. tertium could contaminate eggshells and infect embryos and chickens. If this assumption is correct, appropriate preventive countermeasures could be implemented in the poultry industry.

\section{REFERENCES}

Berrang M.E., Frank J.F., Bur R.J., Bailey J.S., Cox N.A., 1999. Eggshell membrane structure and penetration by Salmonella Typhimurium. J. Food Protect. 62, 73-76

Binek M., Borzemska W., Pilarski R., Błaszczak B., Kosowska G., Malec H., 2000. Evaluation of the efficacy of feed providing on development of gastrointestinal microflora of newly hatched broiler chickens. Arch. Geflugelk. 64, 147-151

Cook M.I., Beissinger S.R., Toranzos G.A., Rodriguez R.A., Arendt W.J., 2003. Trans-shell infection by pathogenic micro-organisms reduces the shelf life of non-incubated bird's eggs: a constraint on the onset of incubation? Proc. Roy. Soc. London, Ser. B 270, 2233-2240

Hess L., Bartick T., Hoefer H., 1998. Clostridium tertium in Moluccan cockatoo with megacolon. J. Avian Med. Surg. 12, 30-35

Malicki K., Binek M., 2004. Outline of the Clinical Veterinary Bacteriology (in Polish). Editor: Warsaw Agricultural University

Miller D.L., Brazer S., Murdoch D., Reller B., Corey G.R., 2001. Significance of Clostridium tertium bacteremia in neutropenic and nonneutropenic patients: review of 32 cases. Clin. Infect. Dis. $32,975-978$

Montgomery R.D., Jones L.S., Boyle C.R., Luo Y., Boyle J.A., 2005. The embryo lethality of Escherichia coli isolates and its relation ship to various in vitro attributes. Avian Dis. 49, 63-69

Rosario C.C., Tellez G.I., Lopez C.C., Mateo J.V.F., Anderson R.C., Eslava C.C., 2004. Bacterial isolation rate from fertile eggs, hatching eggs, and neonatal broilers with yolk sac infection. Rev. Latinoamer. Microbiol. 46, 12-16

Silvera M., Finn B., Reynolds K.M., Taylor DJ., 2003. Clostridium tertium as a cause of enteritis in cattle. Vet. Rec. 153, 60

Steyaert S., Renaat Peleman R., Vaneechoutte M., De Baere T., Claeys G., Verschraegen G., 1999. Septicemia in neutropenic patients infected with Clostridium tertium resistant to cefepime and other expanded-spectrum cephalosporins. J. Clin. Microbiol. 37, 3778-3779

Tankson J.D., Thaxton J.P., Vizzier-Thaxton Y., 2001. Pulmonary hypertension syndrome in broiler caused by Enterococcus faecalis. Infec. Immunity 69, 6318-66322

Tankson J.D., Thaxton J.P., Vizzier-Thaxton Y., 2002. Bacteria in heart and lungs of young chicks. J. Appl. Bacteriol. 92, 443-450 